\title{
Strategic Human Resource Management, Regulatory Violation and Job Satisfaction in Indonesia
}

Indra Anggraeni, Eny Lestari Widarni

(STIE Jaya Negara Tamansiswa Malang)

\begin{abstract}
This study aims to investigate the level of employee job satisfaction, employee compliance with work regulations and strategic human resource management by conducting online interviews with 349 government and private employees in Indonesia by random sampling using the LinkedIn application then quantifying them for regression using the autoregression moving average model. We find that the level of employee satisfaction is positively related to employee compliance with job regulations and the level of quality management of strategic resources in companies or government institutions.
\end{abstract}

Keywords : Human Resource Management, Job Satisfaction, Employees

\section{Background}

Strategic human resource management is an important factor in modern business (Bailey et al,2018). Because human resource management determines the performance of human resources in the organization. Human resource management also plays a role in meeting the human resource needs of the organization and developing the human resources that have been recruited. Employees are valuable assets of both private and government organizations.

Quality strategic human resource management can maintain employee satisfaction and employee performance so that they can contribute optimally to the organization (Widarni \& Bawono,2020). Job satisfaction and good strategic human management will have an impact on the minimal violation of work rules that have been agreed and made within the organization. Employee job satisfaction can improve performance and keep employees working with the organization (Karadağ,2015). Job satisfaction must be maintained to improve employee performance and of course improve organizational performance to achieve organizational goals.

\section{Literature Review}

Strategic human resource management has a good impact on employee performance (Widarni,2020). Strategic human resource management encourages employee performance and employee attitudes and behaviour through procedures or work policy collections. Strategic human resource management aims to manage employees according to the needs of the organization with high performance and good behaviour. Strategic human resource management policies greatly influence attitudes and behaviours 
that have an impact on employees as a whole. The leadership of company leaders also needs to be regulated through policies because leadership greatly impacts the performance of implementing employees (Weiss et al,2019).Violation of work rules can interfere with performance or actually increase performance depending on the violation and applicable rules. If the prevailing regulations actually decrease performance, it is necessary to make changes to regulations that are more dynamic and in accordance with performance requirements. However, if the violation causes performance to decrease and endangers the organization, it is precisely necessary to have fair logical consequences between employees and the company.

Employees may break rules for organizational gain such as breaking rigid and bureaucratic rules for a job that requires dynamism (Alvesson \& Sveningsson,2019). Therefore, every violation needs to be studied wisely, whether the rules are problematic or the employees are problematic, this is necessary for strategic human resource management to maintain work comfort, job satisfaction and improve performance. Violations that damage and harm the organization, of course, must be dealt with firmly. However, violations that are committed for a reason that actually benefit the organization and do not cause harm need to be reviewed and evaluated on the prevailing regulations and policies. Job satisfaction is a condition in which employees feel comfortable and at ease working and feel satisfied with the results obtained from the best contribution needed by the company or organization. Job satisfaction is closely related to welfare, rewards and work comfort (McKee, 2017).

\section{Research Method}

Collecting data in this study using interviews with 349 government and private employees in Indonesia by random sampling using the LinkedIn application then quantifying for regression using the autoregression moving average model. The interview aims to extract data in the form of employee satisfaction levels, employee compliance, quality levels of strategic resource management. We use average data or all the data obtained is averaged based on a group of variables determined based on literature review and background and time series, then the regression is carried out using the moving average model autoregression method with the following equation:

$S_{t}=C_{t}+\beta_{1} E_{t 1}+\beta_{2} H_{R M S}+e_{t}$

Where,

$\mathrm{S}=$ level of employee satisfaction

$\mathrm{E}=$ Employee compliance

HRMS = Quality level of strategic resource management

$\mathrm{e}=$ Term Error

\section{Result and Discussion}

The estimation results are as follows:

$\mathrm{S}=-0.602806335093+0.0552931369825 * \mathrm{E}+0.956793553765 * \mathrm{HRMS}$

From the estimation results, the level of employee compliance and the quality level of strategic human resource management have a positive effect on the level of employee satisfaction. Where every $1 \%$ increase in the level of employee satisfaction is followed by an increase in employee compliance by 
$0.05 \%$ and the quality of strategic human resource management by $0.9 \%$ which is briefly described in Table 1 illustrates the estimation results as follows:

Table 1. Estimation Results

\begin{tabular}{|c|c|c|c|c|}
\hline Variable & Coefficient & Std. Error & t-Statistic & Prob. \\
\hline $\mathrm{C}$ & -0.602806 & 1.249629 & -0.482388 & 0.6357 \\
\hline $\mathrm{E}$ & 0.055293 & 0.228196 & 0.242306 & 0.8114 \\
\hline HRMS & 0.956794 & 0.210936 & 4.535938 & 0.0003 \\
\hline R-squared & 0.825511 & \multicolumn{2}{|c|}{ Mean dependent var } & 7.25 \\
\hline Adjusted R-squared & 0.793218 & \multicolumn{2}{|c|}{ S.D. dependent var } & 1.446411 \\
\hline S.E. of regression & $8.01 \mathrm{E}-01$ & \multicolumn{2}{|c|}{ Akaike info criterion } & 2.531911 \\
\hline Sum squared resid & 10.91095 & \multicolumn{2}{|c|}{ Schwarz criterion } & 2.681271 \\
\hline Log likelihood & -22.31911 & \multicolumn{2}{|c|}{ Hannan-Quinn criter. } & 2.561068 \\
\hline F-statistic & 22.4666 & \multicolumn{2}{|c|}{ Durbin-Watson stat } & 1.653996 \\
\hline Prob(F-statistic) & \multicolumn{4}{|c|}{0.000017} \\
\hline
\end{tabular}

Based on the estimation results described in Table 1. The level of employee satisfaction reflects the level of employee compliance and the quality level of strategic human resource management. The following is a forecasting of the level of job satisfaction of employees in Indonesia from 2000 to 2019 in Figure 1 as follows:

Figure 1. The results of forecasting the level of job satisfaction of employees in Indonesia

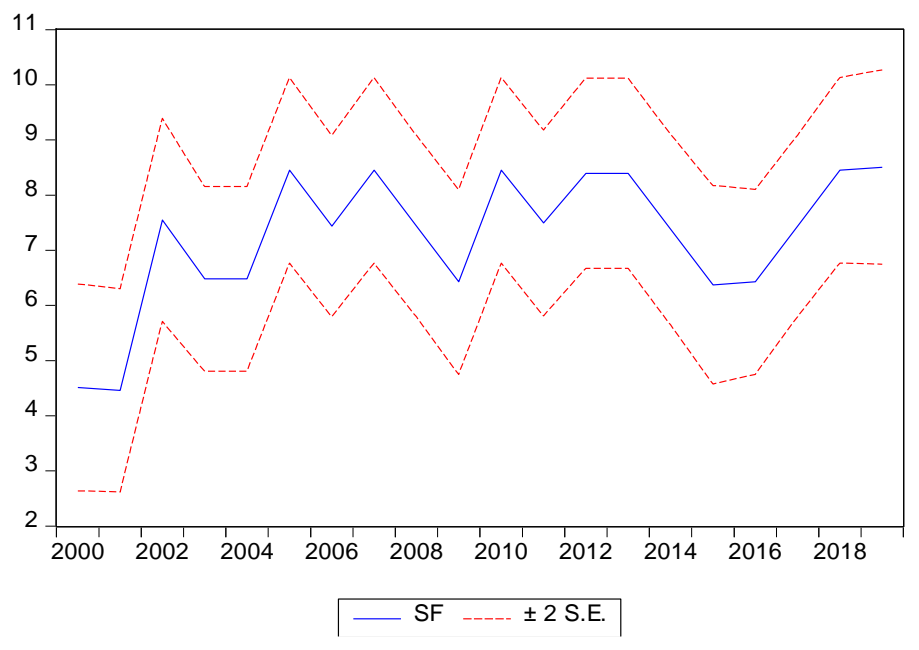

\begin{tabular}{|c|c|}
\hline \multicolumn{2}{|l|}{ Forecast: SF } \\
\hline \multicolumn{2}{|l|}{ Actual: S } \\
\hline \multicolumn{2}{|l|}{ Forecast sample: 20002019} \\
\hline \multicolumn{2}{|l|}{ Included observations: 20} \\
\hline Root Mean Squared Error & 0.738612 \\
\hline Mean Absolute Error & 0.626313 \\
\hline Mean Abs. Percent Error & 9.859198 \\
\hline Theil Inequality Coefficient & 0.050128 \\
\hline Bias Proportion & 0.000000 \\
\hline Variance Proportion & 0.080048 \\
\hline Covariance Proportion & 0.919952 \\
\hline Theil U2 Coefficient & 0.377012 \\
\hline Symmetric MAPE & 9.531229 \\
\hline
\end{tabular}

Source: Author's computation

Based on the forecasting results in Figure 1, the development of employee job satisfaction levels in Indonesia tends to fluctuate according to work conditions. This proves that human resource management is important for maintaining the level of employee job satisfaction which in turn has an impact on employee performance.

\section{Conclusion}

Employee job satisfaction is very important to maintain employee loyalty and employee performance so that they can make the best contribution to the company. Employee satisfaction is positively related to the quality level of strategic human resource management and the level of employee compliance in the company. 


\section{Reference :}

Alvesson,M., Sveningsson,S.(2019).Changing Organizational Culture: Cultural Change Work in Progress. London: Routledge

Bailey,C., Mankin,D, Kelliher,C.(2018).Strategic Human Resource Management. Oxford: Oxford University

Karadağ,E.(2015).Leadership and Organizational Outcomes: Meta-Analysis of Empirical Studies. Cham : Springer

McKee,A.(2017).How to Be Happy at Work: The Power of Purpose, Hope, and Friendship.Boston : Harvard Business School Publishing

Weiss,S.A., Tappen,R.M. ,Grimley,K.(2019).Essentials of Nursing Leadership \& Management.Philadelphia: F.A. Davis.

Widarni,E.L.(2020).Human Capital Frameworks: How to Build a Strong Organization.New York : Lulu

Widarni,E.L., Bawono,S.(2020).The Basic Of Human Resource Management Book 1. Munich : BookRix 